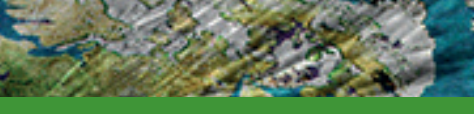 \\ Ecología y bioética
}

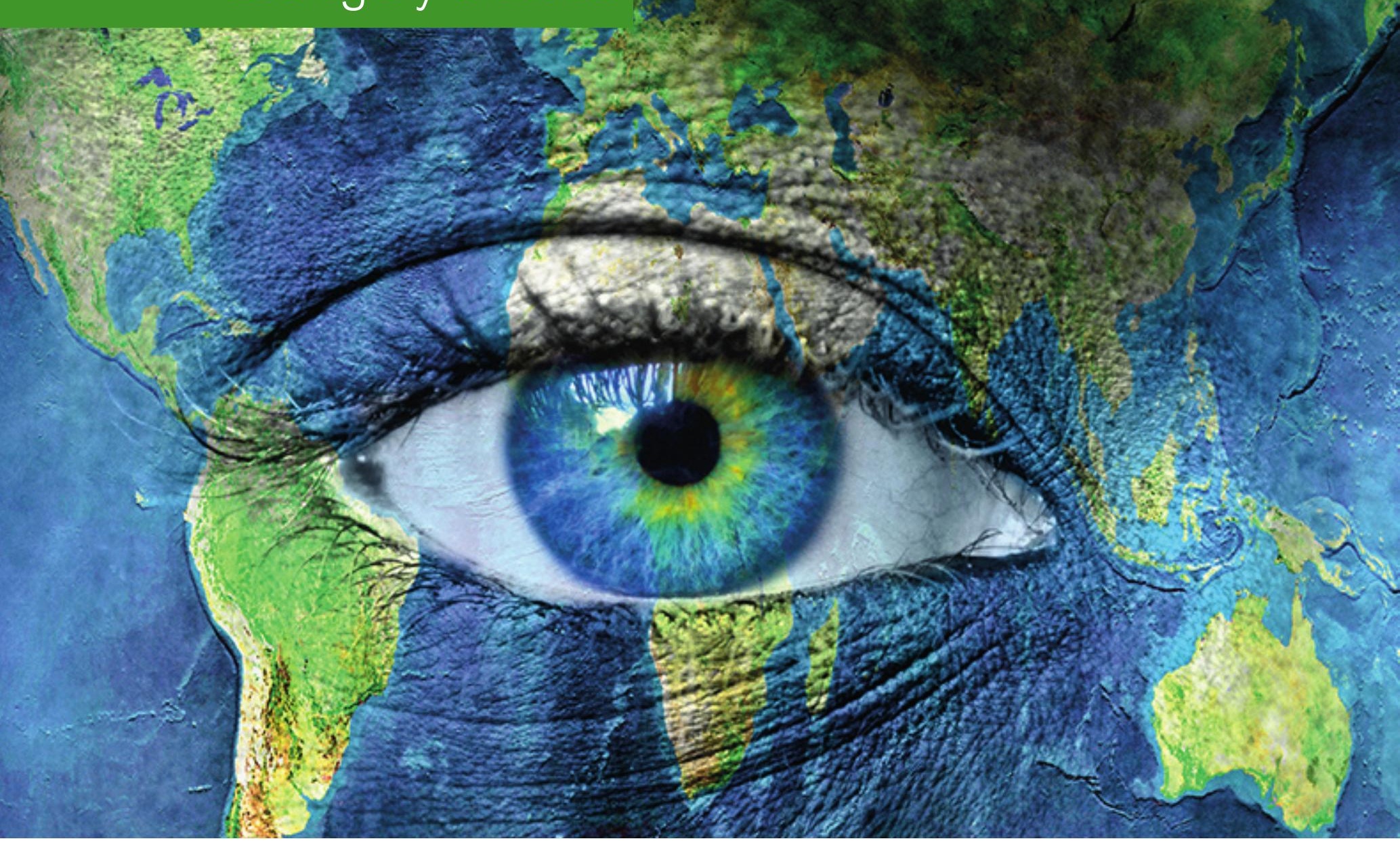

\section{Crise ambiental e crise ético-moral na perspectiva da Laudato si'}

The environmental and the ethical and moral crises according to the Laudato si' encyclical
(2) Autor
Leo Pessini
Professor do Programa de Pós-Graduação Stricto Sensu em Bioética do Centro Universitário São Ca- milo de São Paulo
E-mail: pessini@saocamilo-sp.br
Anor Sganzerla
Professor do Programa de Pós-Graduação Stricto Sensu em Bioética da Pontifícia Universidade Cató- lica do Paraná
E-mail: anor.s@pucpr.br 
Resumo

Abstract

Key words

\begin{abstract}
Diante do modo desordenado de conceber a vida no atual modelo de desenvolvimento político e econômico, que tem comprometido a casa comum devido à depredação da totalidade da vida da biosfera, e com a crise ética e moral de nossos tempos que tem propiciado uma cultura do relativismo, do descartável e do imediatismo, está reflexão quer analisar como o Papa Francisco relaciona a crise ambiental com a crise ético-moral em sua Encíclica Laudato si'. Opondo-se a visão de que vivemos uma época de diferentes crises, o pontífice afirma que vivemos uma única e complexa crise socioambiental, e que essa crise socioambiental é a manifestação externa da crise ética-moral, cultural e espiritual da humanidade. 0 grito da Terra é inseparável do gemido dos pobres, por isso, somente uma ecologia integral poderá superar a cura das relações humanas fundamentais.
\end{abstract}

Faced with the disorderly way of conceiving life in the current model of political and economic development, which has compromised our common home due to the depredation of all forms of life in the biosphere, and in light of the moral and ethical crisis of our time that has fostered a culture of relativism, disposability and immediacy, this reflection aims to analyze how Pope Francis connects the environmental crisis with the ethical and moral crisis in his Laudato si' encyclical. Pope Francis believes that we do not live in a time of several crises but rather one complex crisis which is both social and environmental which is the external manifestation of the ethical and moral, cultural and spiritual crisis of humanity. The cry for help of the Earth is inseparable from that of the poor, so only an integral ecology can help heal fundamental human relationships.

Crise; ambiental; ético; moral; Laudato si'.

Crisis; environmental; ethical; moral; Laudato si'.

Recibido: 28/01/2017. Aceptado: 08/05/2017 


\section{Introdução}

Uma das estratégias da Igreja para promover a sua doutrina e orientar os religiosos e fiéis em todo o mundo é a publicação das Encíclicas. Embora possa ser considerada uma prática comum de todos os pontífices, o Papa Francisco, com a publicação da Encíclica Laudato si' (2015) provocou uma verdadeira "revolução" não somente para os "crentes", mas também para os "não-crentes", uma vez que a Encíclica questiona o atual modo de vida, de produção, de con-

O Papa Francisco com a

Encíclica Laudato si': sobre

o cuidado da casa comum

questionou a humanidade para

repensar sobre o atual modelo

de desenvolvimento, bem como

o modo como conduzimos a

nossa vida, que tem ameaçado

a nossa comum sumo, e o modelo político e econômico.

Antes mesmo do seu anúncio oficial, o documento pontifício criou uma enorme expectativa mundial sobre o conteúdo nele presente. Em termos de informação, o documento causou um mal-estar, especialmente em certos setores dos EUA, ligados às indústrias do petróleo e do carvão, pois mexeu com gigantescos interesses políticos e econômicos. Se o Papa Leão XIII (1879-1903) com a Encíclica Rerum Novarum: sobre a condição operária assombrou o mundo da época, o Papa Francisco com a Encíclica Laudato si': sobre o cuidado da casa comum questionou a humanidade para repensar sobre o atual modelo de desenvolvimento, bem como o modo como conduzimos a nossa vida, que tem ameaçado a nossa comum.

A fonte de inspiração da Encíclica também merece destaque. 0 pontífice inicia o documento revelando que sua fonte de inspiração para a Encíclica é São Francisco de Assis, chamado por ele de "exemplo por excelência de cuidado pelo que é frágil (...) pela sua atenção especial aos pobres e abandonados (...) por uma ecologia integral" (LS, no 10) 1. A forma simples e harmoniosa que Francisco vivia com Deus, com os outros, com a natureza e consigo mesmo, também são profundamente reconhecidos pelo pontífice. Afirma que "nele [Francisco] se nota até que ponto são inseparáveis a preocupação pela natureza, a justiça para com os pobres, o empenho da sociedade e a paz interior" (LS, $\left.n^{\circ} 10\right)$.

A Encíclica usa expressões que revelam a cultura ecológica do pontífice, tais como: "casa comum", "mãe Terra", "grito da Terra e do grito dos pobres", "cuidado", interdependência entre todos os seres, "pobres e vulneráveis", "mudança de paradigma", "ecologia integral", "ser humano como Terra" que sente, pensa, ama e venera, entre outros. Além disso, o documento se utilizada de uma metodologia Latino Americana conhecida nas palavras ver, julgar, agir e celebrar. Este método obriga a considerar as realidades concretas, a partir dos desafios reais, e não de doutrinas a partir das quais se fazem deduções, geralmente abstratas e pouco mordentes quando referidas aos temas suscitados. Esse método obriga a incorporar os dados mais seguros das ciências da vida e da Terra entre outras.

1 As referências à obra Laudato si': sobre o cuidado da casa comum, do Papa Francisco serão feitas pelas iniciais da Encíclica (LS) seguida do número do parágrafo do documento. 
O documento faz uma severa crítica ao nosso modo de vida baseado no consumo, no desperdício, no descarte e na mentalidade de que somos donos da natureza, e de que seus recursos são infinitos. Essa cultura, por sua vez, que

Como consequência dessa ação individual e egocêntrica, o homem passa a viver uma crise existencial, ética, moral, ambiental e tantas outras, não conseguindo identificar uma relação entre elas, mas somente problemas isolados e independentes "afeta tanto os seres humanos excluídos como as coisas que se convertem rapidamente em lixo" (LS, $\left.n^{\circ} 22\right)$, não tem favorecido para a realização humana, porque o homem tem buscado a sua realização independentemente das outras esferas da existência. Como consequência dessa ação individual e egocêntrica, o homem passa a viver uma crise existencial, ética, moral, ambiental e tantas outras, não conseguindo identificar uma relação entre elas, mas somente problemas isolados e independentes. Afirma o Pontífice que muitos dos defensores das mais diferentes causas e movimentos ecologistas "(...) defendem a integridade do meio ambiente e, com razão, reclamam a imposição de determinados limites à pesquisa científica, mas não aplicam estes mesmos princípios à vida humana" (LS, n 136), aceitando que se ultrapasse os limites quando se faz experiências com embriões humanos vivos. É desse descompasso entre crise ambiental e crise ético-moral que nos ocuparemos a seguir.

\section{Crise ambiental}

O nosso atual modelo de viver, de habitar e de se relacionar com a natureza, está sendo profundamente questionado por muitos. Nele se identifica uma forma perigosa, ameaçadora e comprometedora da vida, principalmente em relação à continuidade autêntica da humana e da vida extra-humana no futuro (Jonas, 2006). Trata-se de um modelo que exclui a maioria da humanidade do acesso às condições mínimas de sobrevivência, embora se justifique a destruição dos recursos naturais como uma necessidade para atender os interesses da humanidade.

Até o século $X X$ o pressuposto da ética tradicional era de que a fragilidade da vida era somente da vida humana, sendo que a natureza cuidada de si mesma, e, desse modo, não necessitaria do cuidado ético e humano. Além disso, partiu-se da ideia de que homem com seu poder seria incapaz de fazer qualquer modificação na natureza, na medida em que seu ciclo e sua essência eram imodificáveis pelo agir humano (Jonas, 2006, p. 33). Desse modo, a ética se reduzia ao âmbito da cidade, nas relações entre os humanos, sendo os grandes muros de proteção das cidades justificados como medida de segurança diante do poder natural.

Essa perspectiva antropocêntrica foi defendida por vários pensadores, em destaque com a filosofia de Francis Bacon, em sua obra Novum Organum, no século XVI, no qual afirmou o pensador que "o homem, ministro e intérprete da natureza, faz e entende tanto quanto constata, pela observação dos fatos ou pelo trabalho da mente, sobre a ordem da natureza, não sabe, nem pode mais" (1999, p. 33). Ao declarar o homem como ministro e intérprete da natureza, Bacon reforçou a ideia de que a natureza não possui 
uma teleologia e nem uma moralidade, o que autoriza o homem agir de modo que possa extrair dela todos os seus segredos, mesmo que para tanto, precise torturá-la, uma vez que ela se compreende como matéria "morta" e disponível para a exploração e manipulação humana. O programa baconiano, com o lema "saber é poder" revela que a meta é a instauração do regnum hominis. A filosofia de Bacon, pode ser considerada o símbolo do pensamento Ocidental.

Esse modo de pensar favoreceu com que seres vivos presentes na natureza fossem tratados como coisas, afirma Kant, o símbolo da ética moderna. Afirma o pensador que os seres cuja existência depende da natureza tem um valor relativo como meios e por isso se chamam coisas, ao passo que os seres racionais se

A dimensão antropocêntrica defende que agir eticamente significa limitar o uso dos

recursos da natureza, para que os mesmos não faltem às gerações futuras chamam pessoas, porque sua natureza os distingue como fins em si mesmos. E que no reino dos meios as coisas têm preço, mas o homem tem dignidade, por isso merecedor de respeito moral (Kant, 2005).

Ao analisar a perspectiva antropocêntrica que prevaleceu em nossa cultura, o pontífice afirma que esse modo de pensar no qual o homem entende e se relaciona com a natureza como um estoque de recursos naturais para o proveito humano, fez com que o homem "já não sinta mais a natureza como norma válida, nem como um refúgio vivente" (LS, $\mathrm{n}^{\circ}$. 115). E acrescenta o pontífice que foi essa visão que alimentou uma mentalidade predatória e destruidora da natureza, uma vez que os recursos naturais estão à disposição do desfrute ilimitado do ser humano: "um antropocentrismo desordenado gera um estilo de vida desordenado" (LS, n 122).

Essa dimensão antropocêntrica, por sua vez, defende que agir eticamente significa limitar o uso dos recursos da natureza, para que os mesmos não faltem às gerações futuras. Embora essa concepção demostre certa preocupação com a sustentabilidade, ela se limita à esfera humana, ou seja, é necessário preservar a natureza em vista da continuidade da vida humana, o que ficou conhecido como ética da conservação da natureza. A dignidade da natureza por si mesma, não tem espaço nesse tipo de mentalidade. As críticas do pontífice a essa concepção antropocêntrica de mundo perpassam toda a Encíclica, e o faz como uma espécie de denúncia, principalmente em relação à tecnociência por apresentar-se como a única opção à humanidade "condicionando a vida das pessoas e o funcionamento da sociedade" (LS, n 107).

\section{Crise humana e dos valores}

Esse modo de ver o mundo unicamente a partir da perspectiva e dos interesses humanos, apesar de aparentar-se como a única forma de compreender o homem, é na realidade, uma forma enganosa de explicar o homem e sua relação com o reino da vida, porque o homem não se compreende de modo isolado da natureza e da transcendência, visto que ele é parte e fruto da natureza e da própria transcendência. No entanto, ao conceber-se acima e separado das outras realidades, o homem passou a manter uma relação de superioridade para com a natureza, e de indiferença para com o transcendente, autorizando-se, desse modo, a agir sem limites. 
Essa perspectiva antropocêntrica de mundo, encontrou ressonância na cultura dualismo presente em nossa sociedade, o que fez com que parte da biosfera perdesse a sacralidade, a axiologia e a ontologia, promovendo desse modo, uma ruptura ontológica do homem, em relação à natureza, ao criador e com ele mesmo. Afirma o pontífice que "se o ser humano não redescobre o seu verdadeiro valor, compreende-se mal a si mesmo e acaba contradizendo a sua própria realidade" (LS, $\left.n^{\circ} 115\right)$, e passa a buscar a sua realização não mais em sintonia com a natureza e com a transcendência, mas sim a partir dos ideais utópicos ofertados pela tecnociência, com seus pressupostos de superação e de progresso.

A tecnociência se tornou
tecnocracia, uma verdadeira
ditadura com sua lógica férrea
de domínio sobre tudo e sobre
todos

A tecnociência se tornou tecnocracia, uma verdadeira ditadura com sua lógica férrea de domínio sobre tudo e sobre todos, afirma o pontífice. A grande ilusão, hoje dominante, reside na crença de que com a tecnociência se podem resolver todos os problemas ecológicos. Essa é uma diligência enganosa porque "implica isolar as coisas que estão sempre conexas" (LS, $\left.n^{\circ} 220\right)$, pois "tudo está relacionado (...) e tudo está em relação" (LS, n 127). 0 grande limite da tecnocracia está no fato de "fragmentar os saberes e perder o sentido de totalidade" (LS, $\left.\mathrm{n}^{\circ} 110\right)$, e como consequência, não ser capaz de "reconhecer nos outros seres um valor próprio (...) ou até mesmo com a negação do valor peculiar do ser humano" (LS, n 118).

Isolado e independente dentro da biosfera, o homem passou a buscar a sua salvação nos avanços da tecnociência. Nela ele identificou as possíveis promessas e esperanças para a sua plena realização humana. A crítica de Jonas a essa concepção se dá porque para o pensador a tecnociência, que se apresenta como esperança de salvação da humanidade, tem uma essência niilista, ou seja, não há valores nela presentes de modo a beneficiar a humanidade, mas somente vontade de poder de buscar a própria autossuperação em vista de seu próprio engrandecimento.

Desse modo a "nova" forma do niilismo passou a ser que a "maior das capacidades", isto é a capacidade tecnocientífica, tenha se unido ao "menor dos saberes", na medida em que a técnica não pensa em si mesma nem como técnica e muito menos como poder. 0 niilismo que impediu o homem de perguntar sobre o seu poder transformou-o num objeto da técnica: “(...) com o niilismo o maior dos poderes se uniu ao maior dos vazios; e a maior das capacidades, ao menor dos saberes sobre para que utilizar tal capacidade" (Jonas, 2006, p. 65)

Se o niilismo é a total perda do sentido, a desvalorização de todos os valores, como havia também diagnosticado Nietzsche, Sartre, Heidegger, entre outros, agora ele (o niilismo) está associa ao sentimento e à situação de "alienação" vivida pelo homem em relação a si, à natureza e a transcendência. Desse modo, o niilismo tornou inúteis tanto as ações dos homens como o mundo que as sofre. Esse niilismo para Jonas inicia no interior do indivíduo, no sistema de pensamento e de conhecimento, ou seja, na atitude filosófica que consiste na desintegração da própria estrutura ontológica da realidade fora e dentro do homem, e depois acaba consequentemente por transparecer na cultu- 
ra, isto é, naquilo que ele faz e produz como cultura, o que torna a cultura moderna do poder tecnocientífico "um lugar" privilegiado de sua expressão.

Assim sendo, afirma o pontífice, na origem de muitas dificuldades do mundo atual, está principalmente a tendência, nem sempre consciente, de "elaborar a metodologia e os objetivos da tecnociência segundo um paradigma de compreensão que condiciona a vida das pessoas e o funcionamento

Associado a onipresença do

paradigma tecnológico com

a adoração do poder humano

sem limites, se desenvolve

o relativismo ético no qual

tudo o que não serve para

os interesses pessoas e

imediatistas de torna irrelevante da sociedade" (LS, n 107). É preciso reconhecer que os produtos da tecnociência "não são neutros" (LS, n 107) porque criam uma trama que acaba por influenciar os estilos de vida e os próprios interesses de grupos sociais. Jonas também compartilha da ideia de que a tecnociência não é neutra e sim um poder, um movimento que busca a própria autossuperação (Jonas, 2013, p. 51). E para alcançar tal propósito, ela objetivou primeiramente a natureza e depois o próprio homem, reduzindo-o a mero objeto da técnica.

Essa utopia do progresso presente na tecnociência nos faz acreditar que o próprio bem e a própria verdade possam desabrochar espontaneamente do próprio poder da tecnologia e da economia. No entanto, o crescimento tecnológico "não foi acompanhado por um desenvolvimento do ser humano quanto a responsabilidade, aos valores, à consciência" (LS, n 105), visto que ele é conduzido não pelo homo sapiens, mas sim pelo homo faber, e este tem por preocupação unicamente a ideia de autossuperação. Além disso, o princípio regente dessa mentalidade é de que "existe uma quantidade ilimitada de energia e de recursos a serem utilizados, e que a sua regeneração é possível de imediato e que os efeitos negativos dos manipuladores da ordem natural podem ser facilmente absorvidos" (LS, nº 106).

Associado a onipresença do paradigma tecnológico com a adoração do poder humano sem limites, se desenvolve o relativismo ético no qual tudo o que não serve para os interesses pessoas e imediatistas de torna irrelevante. Essa lógica, afirma o pontífice permite compreender como se "alimentam mutuamente diferentes atitudes, que provocam ao mesmo tempo a degradação ambiental e a degradação social” (LS, n 122).

Embora estejamos vivendo um período de extremo perigo e gravidade em relação à continuidade da vida humana e de toda a biosfera no futuro, a forte cultura nilista imobiliza e paralisa as ações humanas, fazendo-nos acreditar que esse é um processo natural.

\section{Ecologia integral}

Em vista de superar a visão antropocêntrica encontra-se as éticas de preservação da natureza, preocupadas com a preservação da natureza em sintonia com o crescimento humano e o florescimento espiritual. Esta perspectiva aponta para valores não-materiais da natureza, e revela que esta detém um valor estético-espiritual (Junges, 2004). Esse modo de pensar, pode ser encontrado desde a cosmovisão estoica, no qual a visão da natureza era pensada como uma solidariedade ética entre todas as coisas exis- 
tentes do universo. Todos têm valor e dignidade ética, por existir, sentir e pensar. Esta é, segundo os estoicos, a escala gradual da dignidade universal: a totalidade de tudo quanto existe, basta existir para ocupar um lugar na escala ética. É este o caminho que nos livra do antropocentrismo, que advoga o valor exclusivamente para o ser humano. Essa arrogância tornou-se a razão instrumental técnica do homo faber.

A cosmovisão antropológica está presente também na filosofia aristotélica, que embora privilegie o homem por ser racional, a mesma reconhece uma teleologia da natureza, e esta finalidade da natureza, não está em oposição à finalidade humana. Esta visão foi herdada pela teologia cristã, apoiada na visão do livro do Gênesis $(3,24)$ que diz que "o homem é o guardião do paraíso". Afirma Pegoraro, que é espantoso constatar que nossa ética milenar "não foi universal, pois envolvia apenas o ser humano; agora, felizmente estamos chegando à ética cósmica, na qual tudo o que existe, no macrocosmo infinitamente grande ou no microcosmo infinitamente pequeno, contém em si na sua existência, dignidade ética" (2014, p. 11).

Pensar a ética não mais na perspectiva antropocêntrica, obriga-nos a reconhecer, assim como os estoicos, que a natureza é Mãe, e que é ela que tudo gera, e por isso,

Todos têm valor e dignidade

ética, por existir, sentir e pensar.

Esta é, segundo os estoicos,

a escala gradual da dignidade

universal: a totalidade de tudo

quanto existe, basta existir para

ocupar um lugar na escala ética merecedora de todo respeito e veneração. Esse reconhecimento de todos os seres como filhos da Natureza, de onde resultava a convivência harmoniosa entre à natureza, o daimon (razão) que habita em cada um de nós e a vontade do governador do universo, consistia a virtude da sabedoria e a felicidade.

Hoje estamos diante de um processo de universalização da ética. Já a ampliamos para várias áreas do mundo: ética da biodiversidade, ética dos animais, bioética humana. A ética transbordou para todas a realidades, trata da proteção das três formas de vida (humana, cósmica e ecológica) e do meio ambiente, onde se desenvolve a vida, como a água, o ar, a luz e os sais minerais. No âmbito desta ética, incluem-se também os produtos da tecnociência (Pegoraro, 2014, pp. 10-13).

A tudo isso, hoje nós chamamos ética da solidariedade antropocósmica: o reconhecimento do valor ético intrínseco à estrutura íntima de cada existência, seja pedra, árvore, pássaro ou ser humano. Esse reconhecimento gera solidariedade, aliança, convívio (oikeiosis estoico) do ser inteligente com o cosmos. Em outras palavras, trata-se da aliança do homem com a natureza, incluindo também a tecnociência que opera sobre a natureza e sobre o homem. Um exemplo desta ética da solidariedade antropocósmica, é o documento da UNESCO (2000), intitulado de A Carta da Terra².

A Encíclica Laudato si', por sua vez, trata da "ecologia integral", que exige uma mudança no estilo de vida, o que requer para tanto uma conversão ecológica. Essa conversação ecológica, afırma o Papa exige em primeiro lugar "gratidão, gratuidade (...) e uma cons-

2 A Carta da Terra é um dos documentos mais preciosos e inspiradores deste início de século XXI, trata-se de uma declaração de princípios fundamentais visando a construção de uma sociedade global no século XXI, que seja justa, sustentável e pacífica. Muitos nutrem a expectativa de que este documento seja incorporado à Carta dos Direitos Humanos de 1948. 
ciência amorosa de não estar separado das outras criaturas, mas de formar com os outros seres do universo uma estupenda comunhão universal" (LS, $\left.n^{\circ} 220\right)$. Trata-se não mais de viver sob a natureza, mas sim de viver com a natureza, pois somos parte e fruto da mesma.

A crise ecológica, afirma o pontífice, é uma "expressão ou uma manifestação externa da crise ética, cultural e espiritual da humanidade (...)" (LS, n 119), e desse modo, não podemos nos iludir de que vamos sanar a nossa relação

Possíveis soluções exigem uma abordagem integral, pois não

podemos pensar no combate

da pobreza, separado do

reconhecimento da dignidade

dos excluídos, junto com o

cuidado da natureza com a natureza, sem antes curar todas as relações humanas fundamentais. Tudo está interligado, afirma o pontífice, e desse modo, quando "não se reconhece a importância de um pobre, de um embrião humano ou uma pessoa com deficiência (...)" (LS, $\mathrm{n}^{\circ}$ 117) dificilmente se conseguirá ouvir o clamor da natureza. E acrescenta o documento que é fundamental buscar soluções integrais que considerem as interações dos sistemas naturais entre si com os sistemas sociais, pois "não há duas crises, separadas: uma ambiental e outra social; mas uma única e complexa crise socioambiental" (LS, n 139). Possíveis soluções exigem uma abordagem integral, pois não podemos pensar no combate da pobreza, separado do reconhecimento da dignidade dos excluídos, junto com o cuidado da natureza.

Ao aproximar meio ambiente, pobreza e dignidade, o Papa incorpora os dados mais consistentes com referência às mudanças climáticas, à questão da água, à erosão da biodiversidade, à deterioração da qualidade da vida humana e à degradação da vida social, denuncia a alta taxa de iniquidade planetária, afetando todos os âmbitos da vida, sendo que as principais vítimas são os pobres. Nesta parte, traz uma frase que nos remete à reflexão feita na América Latina: "hoje não podemos deixar de reconhecer que uma verdadeira abordagem ecológica sempre se torna uma abordagem social, que deve integrar a justiça nos debates sobre o meio ambiente, para ouvir tanto o clamor da terra como o clamor dos pobres" (LS, n 49). A seguir acrescenta: "os gemidos da irmã Terra que se unem aos gemidos dos abandonados deste mundo" (LS, $n^{\circ} 53$ ). Isso é absolutamente coerente, pois logo no início, em referência ao livro do Gênesis, afirma a Encíclica que "nós somos Terra" (LS, n 2).

Ao tratar da Amazônia e da bacia fluvial do Congo, e dos grandes lençóis freáticos e glaciares, o Papa condena a proposta de internacionalização dessas riquezas naturais, e em especial da Amazônia que "apenas serviria aos interesses das multinacionais" (LS, p. 35). Há uma afirmação de grande vigor ético: "é gravíssima iniquidade obter importantes benefícios fazendo pagar o resto da humanidade, presente e futura, os altíssimos custos da degradação ambiental"(LS, nº 38).

Com tristeza reconhece o pontífice: "nunca maltratamos e ferimos nossa casa comum como nos últimos dois séculos" (LS, $n^{\circ} 53$ ). Face a esta ofensiva humana contra a mãe Terra, que muitos cientistas denunciaram como a inauguração de uma nova era geológica -o antropoceno- lamenta a debilidade dos poderes deste mundo que, iludidos, "pensam que tudo pode continuar como está" (LS, $\left.n^{\circ} 55\right)$ como álibi para "manter seus 
hábitos autodestrutivos" (LS, $\left.n^{\circ} 55\right)$ com "um comportamento que parece suicida" (LS, $\left.n^{\circ} 55\right)$. Essa forma de pensar está também em sintonia com o pensamento de Jonas, no qual identifica que quando a humanidade mais precisou da ética, foi quando mais dela nos afastamos (Jonas, 2013, p. 48).

A visão proposta de uma "ecologia integral" do Papa Francisco vai além da costumeira ecologia ambiental. A visão da ecologia integral é sistêmica, integra todas as coisas num grande todo dentro no qual nos movemos e somos. Este

A natureza não é mais

considerada como um mero

instrumento e objeto ao bel

prazer humano, mas como um

organismo vivo, um sistema

aberto, constituído por uma

multiplicidade de vínculos e

inter-relações é o ponto central da construção teórica e prática da Encíclica. Isto implica entender que a economia tem a ver com a política, educação com a ética, ética com a ciência. Todas as coisas relacionadas se entreajudam para existir, subsistir e continuar neste mundo. 0 velho paradigma separava, dicotomizava, atomizava e dividia a realidade em compartimentos. Em vista desta visão distorcida, para cada problema tinha a sua solução especifica sem dar-se conta de sua incidência nas outras partes que podiam ser maléficas.

Necessitamos redesenhar uma nova ética socioambiental, que embora tenha o ser humano como sujeito moral, este deverá ser capaz de colocar no centro da sua visão a reflexão a vida em seu sentido amplo. Os referenciais fundamentais desta nova ética socioambiental são o respeito à alteridade, o cuidado responsável e a solidariedade com a vida em suas múltiplas formas de expressão.

Nesta perspectiva ética, a biosfera ganha um profundo significado moral. Assim superamos o biocentrismo unilateral, bem como uma visão antropocêntrica moderna depredadora da natureza. A natureza não é mais considerada como um mero instrumento e objeto ao bel prazer humano, mas como um organismo vivo, um sistema aberto, constituído por uma multiplicidade de vínculos e inter-relações (Rubio, 2013, p.13).

Trata-se de uma mudança urgente porque chegamos muito tarde neste cenário para intervirmos construtivamente. A humanidade não pode perder mais tempo, porque se a decisão for a de continuar no sistema de vida, desenvolvimento e economia vigentes dominantes, o aumento da temperatura média global poderá chegar de $3^{\circ} \mathrm{C}$ a $4^{\circ} \mathrm{C}$ até 2100. Isto inviabilizará a existência de vida humana no planeta Terra. Isso é o que afirmam, não os "astrólogos" que tentam adivinhar o futuro, mas os estudiosos e cientistas da área ambiental. Se somos a primeira geração a sentirmos os efeitos mais acentuados da destruidora intervenção humana sobre a natureza, os dados da ciência mostram também que somos a última geração que ainda poderá decidir a respeito do tipo de vida que queremos ter futuro. Afirma o pontífice que diante do histórico crescimento ganancioso e irresponsável, que se acentuou nas últimas décadas, "devemos pensar também em abrandar um pouco a marcha, pôr alguns limites razoáveis e até retroceder, antes que seja tarde" (LS, n 193). Nesse sentido a Encíclica de Francisco está em sintonia com a proposta da política do decrescimento.

A Carta da Terra (2000) como bem lembra o Papa Francisco já nos alertava que estamos vivendo um momento crítico da história da Terra, e que chegou a hora da huma- 
nidade escolher o seu futuro. Diz a carta em seu preâmbulo que "(...) ou formamos uma aliança global para cuidar da Terra e uns dos outros ou então arriscamos a nossa própria destruição e a da diversidade da vida".

No fundo da crise ecológica existe, portanto, uma crise de visão do ser humano, dos seus valores culturas e espirituais. Desse modo, para superar a crise ecológica necessitamos de uma nova visão antropológica, e de um novo humanismo, não mais antropocêntrico, dualista e divinizado, com o intuito de dominar a Terra, mas um "humanismo planetário, que comporta uma conscientização da

O ser humano é a Terra que

anda, que ri, que chora, que

canta que pensa, que ama e

que hoje clama por cuidado e

proteção

'Terra-Pátria' como comunidade de destino, de origem e de perdição (L'Yvonnet, 2010, p. 8).

Em discurso na ONU, Boff (2015) afirma que "a Terra é Mãe e é Gaia, geradora de toda a biodiversidade" e que o ser humano dentro da Terra representa um momento mais avançado da evolução e da complexidade da vida, por isso que ele é capaz de "sentir, pensar e amar". Lembra o teólogo que nas línguas neolatinas, a palavra homem vem de húmus que significa terra boa e fecunda, ou a palavra Adão, de adamah, em hebraico-bíblico que significa o filho e a filha da terra fértil. Por isso o ser humano é a Terra que anda, que ri, que chora, que canta que pensa, que ama e que hoje clama por cuidado e proteção.

Inspirado na Carta da Terra, afirma o pontífice para concluir a sua Encíclica que é preciso renovar as esperanças em nossos corações em vista de um futuro mais promissor para a humanidade: "que o nosso tempo seja lembrado pelo despertar de uma nova reverência face a vida, pelo compromisso firme de alcançar a sustentabilidade, a intensificação da luta pela justiça e pela paz, e a alegre celebração da vida" (LS, n 207). Para tanto, devemos mudar nosso olhar sobre a Terra, a natureza e sobre nós mesmos.

\section{Referências bibliográficas}

Bacon, F. (1999). Novum Organum ou verdadeiras indicações acerca da interpretação da natureza. Tradução e notas de José Aluysio Reis de Andrade. São Paulo: Nova Cultural.

Boff, L. (2015). 0 Grito da Terra. O Estado de São Paulo. Caderno aliás. 20 de junho. (2015). Discurso na ONU: Por que a Terra é nossa mãe. Cf. http://leonardoboff.com/. Site acessado em 5 de julho de 2015.

UNESCO (2000). Carta da Terra. Site acessado em 22 de novembro de 2016. Disponível em http://www.mma. gov.br/estruturas/agenda21/_arquivos/carta_terra.pdf.

Cirne, L. F. R. (2013). o espaço da coexistência: uma visão interdisciplinar de ética socioambiental. São Paulo: Edições Loyola.

Bíblia Sagrada (1990). Edição pastoral. $4^{\circ}$ reimpressão. Tradução, introdução e notas de Ivo Storniolo e Euclides Martins Balancin. São Paulo: Edições Paulinas.

Hume, D. (2001). Tratado da natureza humana. Tradução de Débora Danowiski. São Paulo: UNESP. 
Jonas, H. (2006). O princípio responsabilidade: ensaio de uma ética para a civilização tecnológica. Tradução de Marijane Lisboa e Luiz Barros Montez. Rio de Janeiro: Contraponto e Ed. PUC-RJ.

(2013). Técnica, medicina e ética. Sobre a prática do princípio responsabilidade. Tradução do Grupo da ANPOF. São Paulo: Paulus.

Junges, J. R. (2004). Ética ambiental. São Leopoldo: Editora Unisinos.

(2015). Ecologia Integral e justiça ambiental no cuidado da "casa comum". O Ecomenismo de Laudato si': Da Crise Ecológica à Ecologia Integral. Revista do Instituto Humanitas Unisinos - IHU/on-line. Ano XV (469) 104-110.

Kant, I. (2005). Fundamentação da metafísica dos costumes. Tradução de Paulo Quintela. Rio de Janeiro: Edições 70.

L'Yvonnet, F., Prefácio In Morin, E. (2007). Para onde vai o mundo? Petrópolis: Vozes, 7-9.

Maturana, H. \& Varela, F. (2001). A árvore do conhecimento: as bases biológicas da compreensão humana. Tradução de Humberto Mariotti e Lia Dskin. São Paulo: Palas Athena.

Papa Francisco. (2015). Laudato si': sobre o cuidado da casa comum. Carta Encíclica do Sumo Pontífice. São Paulo: Editora Paulus e Loyola.

Pegoraro, O. A. (2014). Ética da Solidariedade Antropocósmica. Rio de Janeiro: Editora Mauad.

Rohden, V. (2005). Viver segundo a ideia de natureza. In Borges, M. L., Heck, J. (Org.). Kant: liberdade e natureza. Florianópolis: Ed. da UFSC, 233-248.

Rubio, A. G. (2013). Prefácio. Cirne, Lúcio F. Ribeiro. O espaço da coexistência: uma visão interdisciplinar de ética socioambiental. São Paulo: Edições Loyola, 9-13.

Serres, M. (1990). O contrato natural. Tradução de Serafım Ferreira. Lisboa: Instituto Piaget.

Sganzerla, A. (2012). Jonas: o homem como ser-na-natureza. In Sganzerla, A., Valverde, A., Falabretti, E. (Org). Natureza humana em movimento: ensaios de antropologia filosófica. São Paulo: Paulus, 322-341.

United Nations (2015). Framework Convention on Climate Change. Adoption of the Paris agreement. Conference of the Parties. Twenty-first session. Paris, 30 November to 11 December 2015. 12 December. 